\title{
Research on the internal pressure behavior of metal gas distribution pipelines with different types of tubing defects
}

\author{
Stefan Mihai Filip ${ }^{1, *}$, and Eugen Avrigean ${ }^{2}$ \\ ${ }^{1}$ Delgaz Grid S.A., Investment Management, Project Team Sibiu, Romania \\ ${ }^{2}$ Lucian Blaga University of Sibiu, Faculty of Engineering, Department of Industrial Machinery and \\ Equipment, Sibiu, Romania
}

\begin{abstract}
The paper aims to approach an important subject related to natural gas distribution networks which, depending on the expansion of the localities, are composed of intercommunicating pipes, pressure reducing stations and branch connections fittings. The urban networks are the most complex ones and the rural areas networks are the simplest. However, irrespective of their installation, they must meet the safety operating requirements as much as possible. According to standards, all these components must be tight and pressure resistant. In this regard, we intend to approach a very important issue related to the behavior of the tubular steel material showing corrosion and/or material defects, and to the internal stress caused by the gas pressure on the walls of the tubing material.
\end{abstract}

\section{Introduction}

The distribution pipelines are usually installed underground at a depth at least equal to the local freezing depth. If we consider classifying the territory of Romania according to the freezing depth standard (STAS 6057-77), in the municipality of Sibiu where we focus the current research, the freezing depth is $900-1000 \mathrm{~mm}$.

The distribution system also includes above-ground pipelines installed in accordance to ANRE approved projects.

The underground distribution pipelines are made of steel or high-density polyethylene, while the above-ground ones are made of steel only.

The distribution pipeline routes are rectilinear as much as possible, along streets or thoroughfares. It is not accepted to install them under or along the tram lines or railroads, or under channels communicating with the neighboring buildings, without special preparation. It is forbidden to pass the distribution pipelines under buildings or their annexes.

The technical regulations for the design, manufacture and operation of gas supply systems (Official Gazette. Part I, no. 255 bis of 2009, as subsequently amended and supplemented), establish the minimum distances between the distribution networks and the different obstacles, buildings or on-route installations.

\footnotetext{
${ }^{*}$ Corresponding author: stefan.filip@hotmail.com
} 


\section{Analyses and Classification of Defects}

The gas distribution piping and its equipment can have a number of defects and imperfections that influence operating safety. The residual mechanical strength and the safe operation of the gas distribution pipelines are essentially determined by the presence of defects. These defects (imperfections with significant negative influences on the correct operation and the bearing capacity of a pipeline) and imperfections (abnormal configuration, size, microstructure, etc, present in the wall of a pipeline that do not inadmissibly affect the bearing capacity of the pipeline) can be classified as:

a. geometric imperfections and defects - deviations in size and shape that significantly change the cross-sectional configuration of the pipe: local gouges and deformations - dents or signs of interaction with external forces.

The local deformations (Fig.1.) are less severe defects or imperfections, since they do not modify the pipe wall thickness, producing only local variations in the curvature of its cross section. The local deformations influence the gas flow in the pipes and may cause major difficulties in carrying out cleaning operations and the internal inspection of the pipes, by blocking the advancement of the intelligent control installations.

The gouges consisting of the local plastic deformation of the pipe and the removal of material by cutting effect are high severity defects or imperfections. When material is removed, the upper layer of the gouge is hammer hardened, so that the presence of these imperfections or defects can result in triggering the processes of cracking and brittle fracturing.
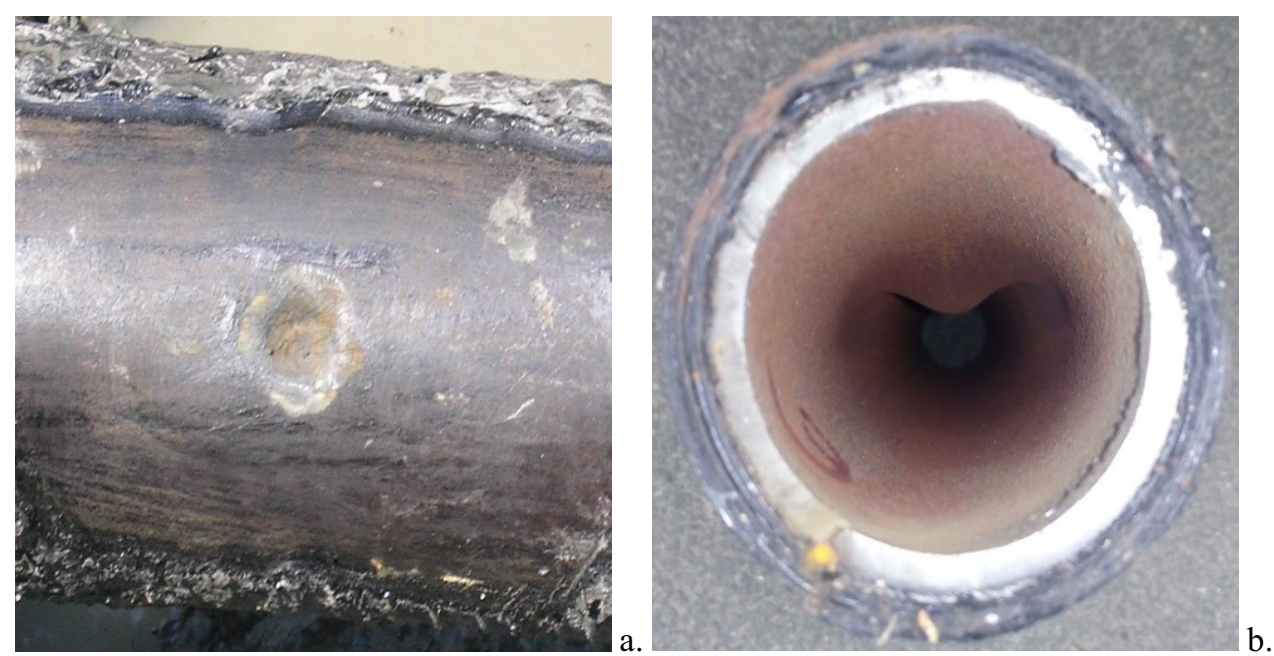

Fig. 1. Local deformation defects detected on pipes

b. metal loss is the imperfection or the defect consisting in the thinning of the pipe wall due to metal loss in the presence or absence of a corrosion process (fig. 2).

c. fissures and cracks (Fig. 3) are the most harmful defects that cause powerful effects of mechanical stresses concentration and noticeably decreases the bearing capacity of the pipelines. These can be generated during the operation of the pipelines, due to the phenomena of fatigue, stress corrosion, hydrogen embrittlement, etc., or they may be present in the pipe walls since its start-up (cracks and similar defects caused by pipe lamination or cracks in the welded joints). 


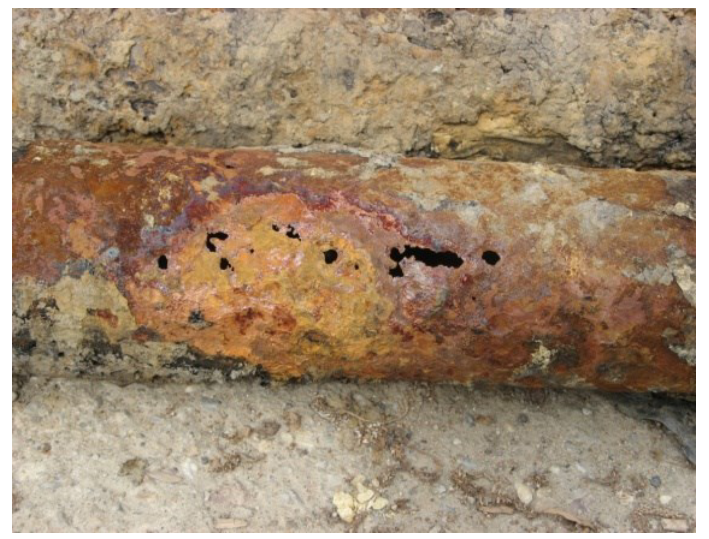

Fig. 2. Metal loss defect due to corrosion

In case of the metal loss type defects subjected to the action of external physical factors (the interaction of the pipe wall with different objects or the slide of the land in the immediate vicinity of the pipeline route) the problems that arise are not clarified and there is no consistent and complete unanimously accepted methodology for assessing the severity of these types of defects.

This category of defects is not classified in certain technical requirements for estimating the residual resistance of the pipelines, and the current norms do not contain a methodology for estimating the severity of these types of defects. [4]
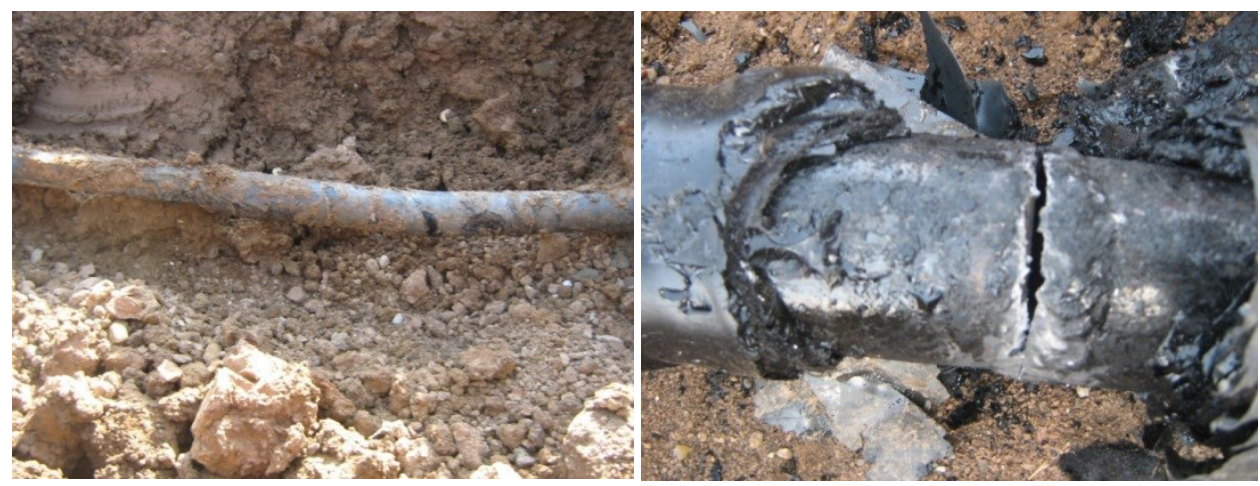

Fig. 3. Cracking defect caused by landslide

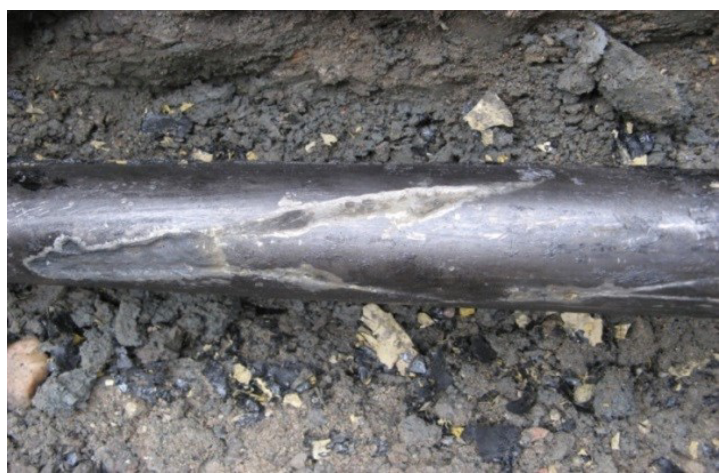

Fig. 4. Metal loss defect detected on a pipeline wall 
In order to assess residual mechanical resistance and the failure probability in operating the pipelines having metal loss defects, it is required to take the following steps:

- classifying the defects, determining the main causes for their appearance on the pipe walls, and establishing the means for detecting them;

- determining the characterization of these defects in terms of size, configuration and changes they cause on the mechanical characteristics of the tubular material;

- establishing the measures to avoid the causes leading to the occurrence of these defects;

- determining the means of correcting the metal loss type defects. [2]

In addition to the metal part defects, the pipelines may also have insulation defects:

- due to incorrect design of the insulating layer and/or failure to follow the applying technology on the insulation ramps or on-site, which happens frequently with the pipes insulated with bitumen and mounted in corrosive soils;

- occurring in pipe sections where the insulation has been pierced during handling in the trench or laying on unprepared surfaces;

- caused by improper weld insulation, according to technical regulations;

- due to foreign bodies in the insulating material;

- occurring in pipelines coming into contact with drains or other pipes, which are not applied a reinforced insulation or are not laid in protective tubes;

- arising from insulation damage caused by interventions to other utilities, when the gas pipeline is covered without restoring the insulating layer;

- caused by probing with tools that damage the protective layer and even the tubular material, like drill bits of the asphalt drilling machines to detect gas leaks;

- due to the improper application of the insulation on the branch tees;

- occurring in the inside, where the pipeline is buried at a greater depth, reaching the maximum camber; where the water is no longer be sucked in the gas flow;

- due to the pores in the tubing material that the insulation cannot cover. [1]

\section{Researches on the Internal Pressure Behavior}

We considered important to know the behavior to the internal pressure of the pipes that have material and corrosion defects, as shown in figures 5. b) and c). For both types of defects we analyzed the same wall thickness.

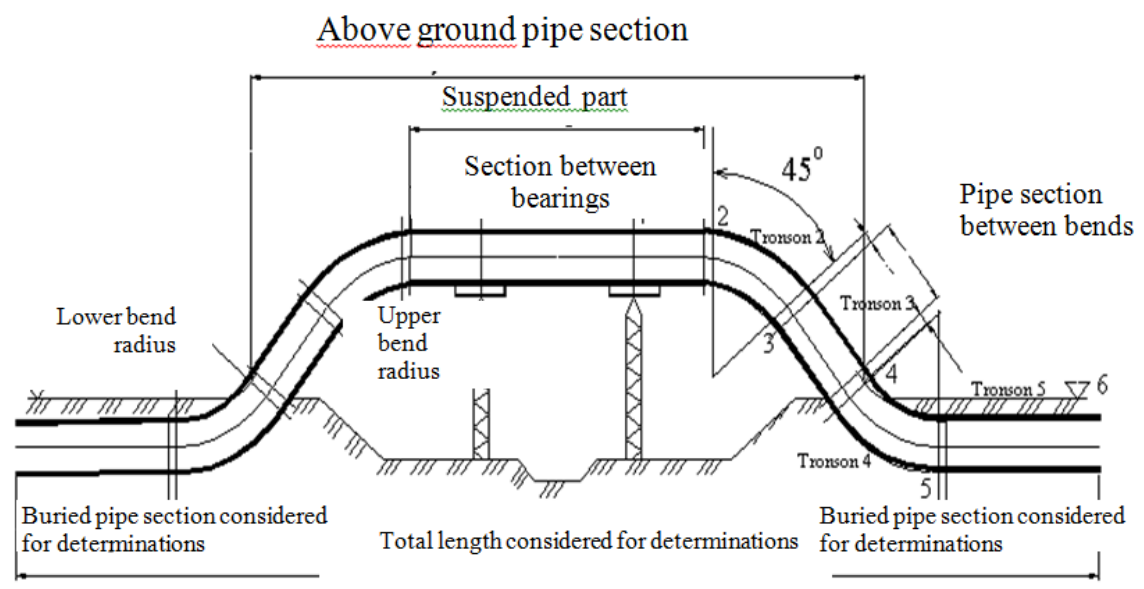

Fig. 5.a. Structure of the pipe subjected to simulation 
The determinations were made by the finite element method on a steel pipe, made of type L235GA material, according to STAS 10208, material that is also called 1.0458 or ST 37.0 according to the former standard DIN EN 12007-3, which crosses over a river and has a structure as shown in Figure 5.a.

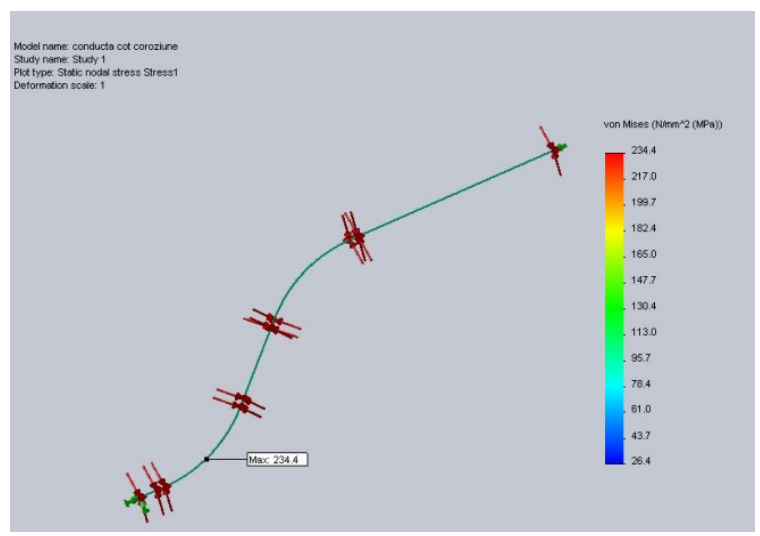

Fig. 5.b. Simulation of a corrosion defect

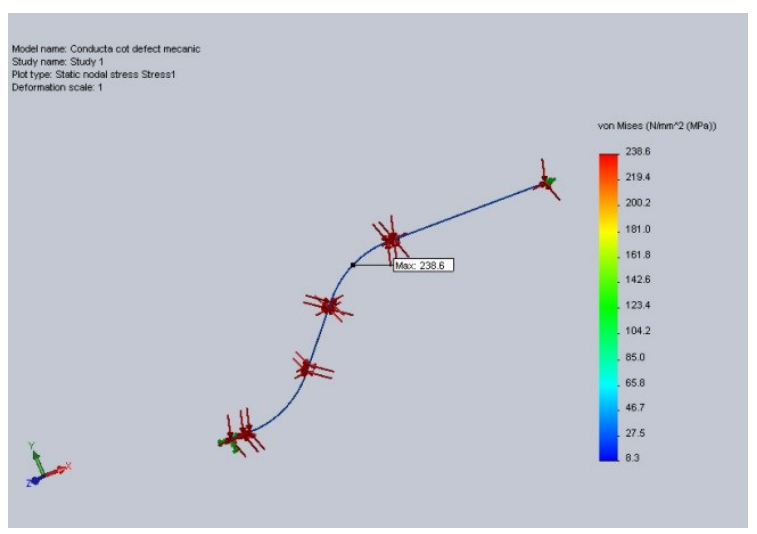

Fig. 5.c. Simulation of a material defect

There have been 6 determinations performed for the values of the wall thickness and the inner pressure shown in Table 1.

The design for the assembly for which the calculus was conducted is shown in figure 5.a), where the positions of the welded joints are marked.

We considered useful that the determinations should be simulated on a pipe section that is part of an assembly of a river overpass, on the grounds that all the defects can be simulated on this type of network; which has led to the simulation of the two types of defects: one corrosion defect found in section where the pipe exits from the ground (considered the section most exposed to corrosion) and one material defect, simulated on the upper bend of the overpass. [5]

After modeling the pipe section subjected to determinations in Catia (a software described in Chapter 4), we simulated the two defects on the section. We did a simulation of the defects for the wall thicknesses shown in Table 1 , for every size we applied an increasing pressure up to the fracture of the pipeline in the defect area, and we also showed the pressure for each defect size in Table 1.

The geometry of the corrosion and material defects is shown in Figures 6 and 7. 


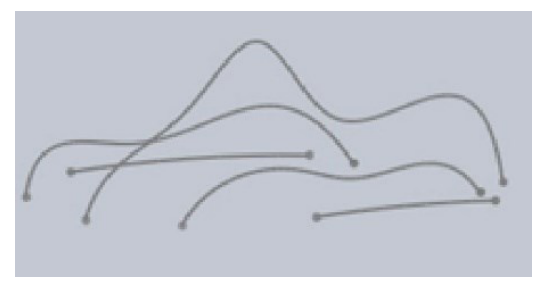

a.

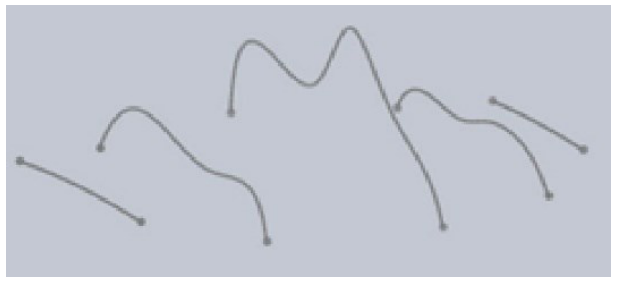

b.

Fig. 6.a. Geometry of the corrosion defect - Curbs defining the defect - side view - a; longitudinal view $-\mathrm{b}$.

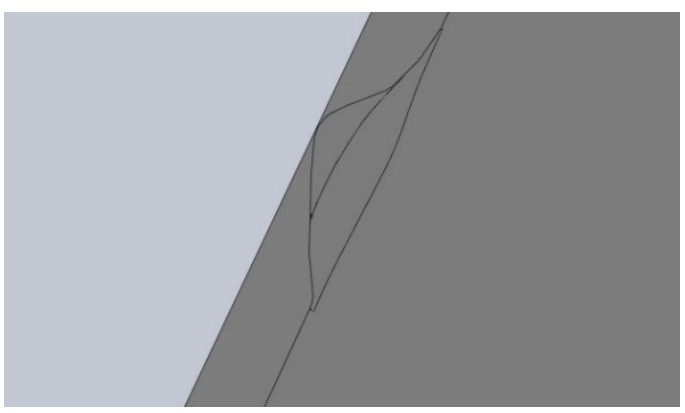

Fig. 6.b. Geometry of the corrosion defect - cross section of the defect in the pipe wall

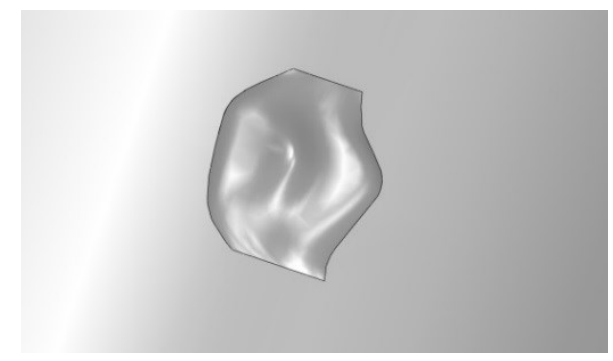

Fig. 6.c. Geometry of the corrosion defect - front view of the defect

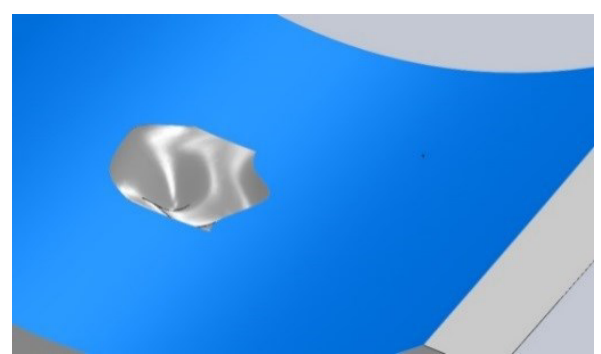

Fig. 6.d. Geometry of the corrosion defect solid view of the defect

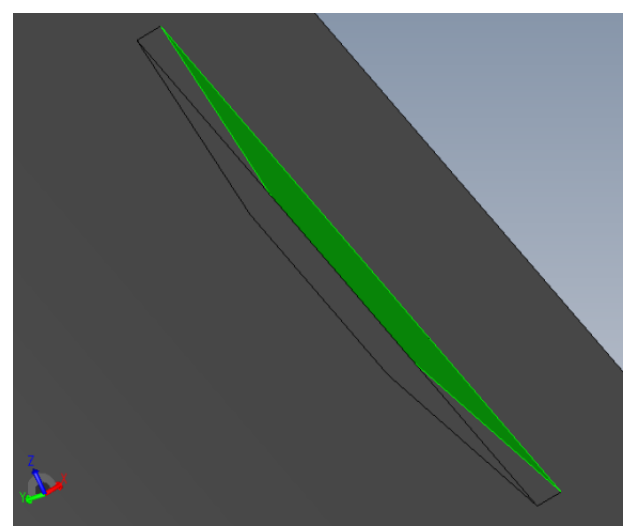

Fig. 7. Image of the material defect 
Table 1. Yield pressure of the tubing

\begin{tabular}{|c|c|c|c|}
\hline \multicolumn{2}{|c|}{ Wall thickness } & \multicolumn{2}{|c|}{$\begin{array}{c}\text { Yield Pressure } \\
\text { [MPa] }\end{array}$} \\
\hline$[\mathbf{m m}]$ & $\mathbf{\%}$ & Material defect & Corrosion \\
\hline 4,5 & 100 & 181 & 181 \\
\hline 2,25 & 50 & 88,9 & 104 \\
\hline 1,125 & 25 & 57 & 103 \\
\hline 0,45 & 10 & 54,4 & 90 \\
\hline 0,225 & 5 & 52 & 86,5 \\
\hline 0,1125 & 2,5 & 33,1 & 84,8 \\
\hline
\end{tabular}

By determining the geometry of the corrosion defect, we tried to simulate the size of a real defect as much as possible (Figure 3), only on the area affected by the pipeline fracture, and not on the entire corroded area. This defect was located on the lower vertical bend which is buried in the ground.

The material defect simulates the damage caused on a pipeline by the tooth of an excavator bucket, not only as a deformation action but as a geometric shape of the blunt body that produces the defect. Assuming that the greatest influence of the operating pressure of the pipeline is in the area of the direction changes, in our case the vertical bends of the overpass, the simulation of the material defect was conducted in this area. [3]

The calculated values of the pressure at which the pipe has yielded in the defect area depending on its depth are shown in Table 1 and the variation graph in Figure 8. [6]

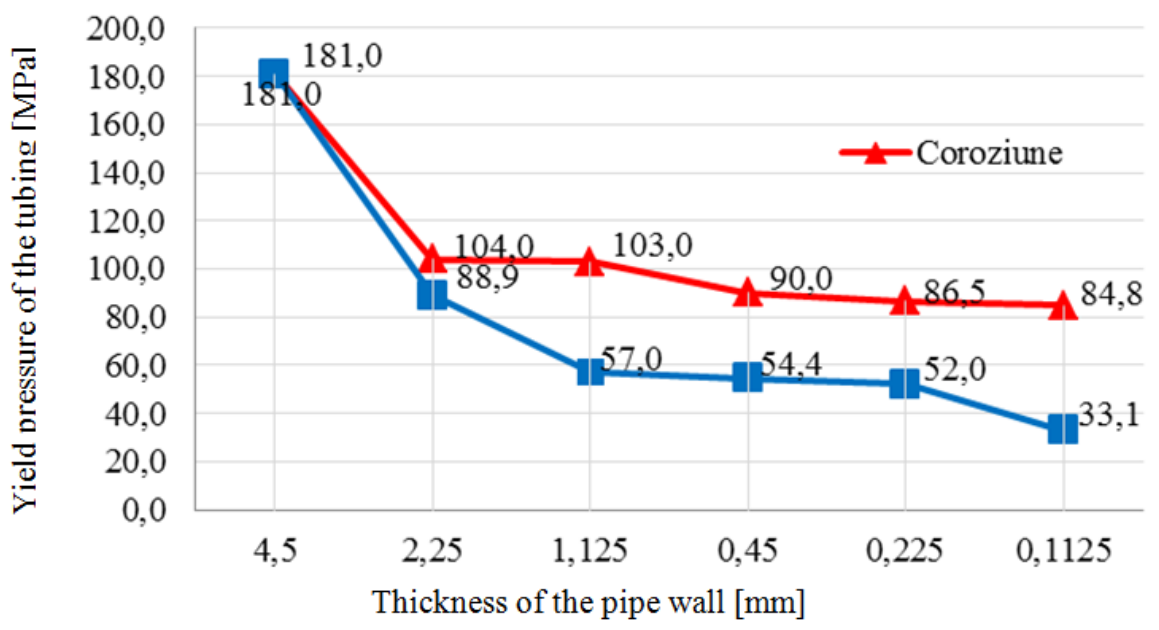

Fig. 8. The piercing pressure according to wall thickness

\section{Conclusions and Recommendations}

Following the theoretical and experimental analyses, we have concluded the following:

- comparing the behavior of the two types of defects under the influence of the internal pressure of the pipeline, we have deduced that, contrary to the initial considerations, in the case of the corrosion defect, the yield pressure of the tubing is higher, under the same wall thickness conditions. We attribute this to the fact that it is possible that the influence should be due to the defects being simulated on the outer side of the pipe and not on its inner side, 
which generates a new hypothesis for future scientific research, related to the simulation and the determination of the maximum tubing yield pressures when there are certain inner material tubing defects;

- the maximum yield pressure corresponds to the lack of material and corrosion defects;

- in case there are material or corrosion defects, the effect is felt when the wall thickness has been reduced by half;

- the minimum yield pressure corresponds to the material defects because they have a larger expansion than the corrosion defects and a geometry that determines the concentration of stresses. [7]

- taking into account these conclusions and determinations, we might suggest as effective measures to help and lead to a better and safer operation, an efficient corrosion protection, both from a passive and an active point of view. Also, another very important aspect in this regard is ensuring an optimal handling of the pipes both during transport and installation.

\section{References}

1. C. Calin, S. Filip, Corrosion protection - less defects, more operational safety (3R International, 2008)

2. Ghe. Zecheru, Ghe. Drăghici, A. Dumitrescu, and P. Iukhymets, Design of Composite Material Reinforcing Sleeves Used to Repair Transmission Pipelines (University of Ploiești Publishing House, Ploiesti, 2014)

3. I. Bondrea, E. Avrigean, Proiectarea constructiva si tehnologica asistata de calculator (Lucian Blaga University Publishing House, Sibiu, 2002)

4. I. Tudor, Materiale speciale si coroziune (University of Ploiesti Publishing House, Romania, Ploiesti, 1992)

5. M. Frăţilă, Acta Universitatis Cibiniensis, XVIII (1996)

6. Ş. Filip, Report no. 2, Cercetări privind evaluarea analitică şi numerică a rezistenţei mecanice a conductelor care prezintă pe tubulatură defecte de tip lipsă de material (University Petroleum-Gas, Ploieşti, 2009)

7. Ş. Filip, Contribuţii privind evaluarea stării de degradare a reţelelor urbane de distribuţie a gazelor naturale (University Petroleum-Gas, Ploieşti, 2016) 